\title{
Adolescents' Victimization and Internalizing Problems: The Protective Role of Parental Sense of Coherence
}

\author{
Silvia Donato $\mathbb{1}^{1} \cdot$ Daniela Barni $^{2} \cdot$ Alice Ferraris $^{1} \cdot$ Raffaella lafrate $^{1} \cdot$ Aryanne D. de Silva $^{3} \cdot$ Mengyu Gao $^{4} \cdot$ \\ Laura E. Miller-Graff ${ }^{3}$ E. Mark Cummings ${ }^{3}$
}

Accepted: 30 January 2022

(c) The Author(s) 2022

\begin{abstract}
Adolescents who are exposed to or involved in violence are at risk of developing internalizing problems; research interest is increasing in identifying family processes that may buffer adolescents' adjustment problems. This study examines parents' sense of coherence (SOC; i.e., parents' perception of comprehensibility, manageability, and meaningfulness in daily life) as a possible protective factor in the relation between adolescents' victimization and internalizing problems. One hundred and forty-eight adolescents (87.7\% girls, aged between 15-19) and their parents (128 fathers and 144 mothers) participated in the study. Parents completed self-report questionnaires including the Sense of Coherence Scale and the Strengths and Difficulties Questionnaire. Adolescents reported about their own experiences of violence (i.e., violence and peer victimization). Results from the path analyses showed that both paternal and maternal SOC were negatively associated with adolescents' internalizing problems. Moreover, paternal SOC, but not maternal SOC, moderated the relation between adolescents' victimization and internalizing problems. When fathers had low levels of SOC, adolescents' victimization was strongly and positively associated with their internalizing problems; on the contrary, for adolescents whose fathers had high levels of SOC the relation between victimization and internalizing problems was not significant. Thus, paternal SOC serves as a resource for adolescents with victimization experiences. We discussed implications and future developments of the study.
\end{abstract}

Keywords Violence $\cdot$ Peer victimization $\cdot$ Parental sense of coherence $\cdot$ Internalizing problems $\cdot$ Adolescents

\section{Highlights}

- Adolescents who are exposed to violence are at risk of developing internalizing problems such as depression and anxiety.

- Parental sense of coherence (SOC) is a protective factor against adolescents'internalizing problems.

- Father's SOC, in particular, buffers the association between adolescents' victimization and internalizing problems.

- Family context is key in creating a safe environment that enhances SOC, which could be targeted in psychosocial interventions.

Silvia Donato

silvia.donato@unicatt.it

1 Family Studies and Research University Centre, Università Cattolica del Sacro Cuore, Milan, Italy

2 Department of Human and Social Sciences, Università degli Studi di Bergamo, Bergamo, Italy

3 Department of Psychology, University of Notre Dame, Notre Dame, USA

4 School of Psychology, Beijing Normal University, Beijing, China
Victimization represents one of the most prominent, preventable threats to children's health and development around the world. In 2014, over 1 billion children globally aged 2-17 years experienced physical, sexual, emotional, or multiple types of violence (Hillis et al., 2016). Such adverse effects of victimization on children's short- and long-term emotional, behavioral, and physical health have been consistently documented (Buka et al., 2001, de Silva et al., 2020, Ford et al., 2010, Turner et al., 2006). Victimization experienced in adolescence may be especially likely to result in internalizing problems, such as anxiety and depression. Given the characteristics of this developmental 
period (Erikson, 1968), during which the formation of interpersonal relationships is a crucial task for identity development, being victimized by others can be particularly overwhelming, frightening, and confusing. In light of the adverse effects of victimization, particularly in adolescence, researchers have placed emphasis on identifying individual and contextual resources for preventing both the occurrence and negative effects of youth victimization in various settings (e.g., Patel et al., 2018). Consistent with this line of research, in this study we focused on the negative consequences related to victimization experiences in adolescence, with particular attention paid to the role of parental sense of coherence (i.e., parents' understanding and ability to give meaning to reality; Antonovsky, 1979, 1987) as a resource available in the family context.

\section{Victimization Effects on Adolescents' Adjustment and Resilience}

A large body of work has examined the effects of involvement in and exposure to violence on children's and adolescents' adjustment. The experience of victimization is often associated with lower levels of emotional and social functioning during adolescence (Lätsch et al., 2017, National Academies of Sciences, Engineering, and Medicine, 2016, Pham \& Adesman, 2015, Rigby, 2003). Relative to younger children, adolescents are characterized by an increasing focus on their self and identity (Erikson, 1968), as well as by a tendency to be hyper-aware of others' perceptions (Elkind, 1967), making them particularly sensitive to internalizing problems if exposed to violence. The victimized adolescents, in fact, might believe that they deserve or have somehow caused the victimization, thereby leading to lower self-esteem and self-worth (Graham \& Juvonen, 1998). In particular, victimization has been shown to be linked to adolescents' depressive and anxiety symptoms in various contexts, such as the home (Evans et al., 2008, Wolfe et al., 2003), the school (Flannery et al., 2004, Janosz et al., 2008), and the community (Fowler et al., 2009, Gorman-Smith \& Tolan, 1998). Moreover, victimization in childhood and adolescence is related to longer-term consequences, such as higher levels of mental health problems in adulthood (Källström et al., 2020) or higher likelihood to be involved in violence, either as a perpetrator or a victim, as an adult (Ehrensaft et al., 2003). Nonetheless, youth and families may demonstrate resilience in the aftermath of such experiences, characterized by a diverse range of interpersonal, relational, and contextual strengths (Hamby et al., 2018, Ungar, 2011). Research in the area of resilience has underscored the importance of identifying factors that contribute to children's wellbeing after adversity. Generally speaking, resilience processes may have direct positive effects on children's adjustment (i.e., promotive factors) or buffer relations between adverse experiences and adjustment problems (i.e., protective factors; Masten, 2015). One such factor, which is evaluated in the current study, is the sense of coherence adolescents experienced within the family system.

\section{Sense of Coherence Within The Family: A Resource for The Individual}

Sense of coherence (SOC) is a key concept within the salutogenic model of development, which is focused on promoting growth and adjustment in individuals, beyond preventing risks (Antonovsky, 1996). SOC refers to the pervasive and dynamic feeling of confidence that one's environment is predictable and that things will work out as well as can reasonably be expected. It provides security for individuals managing events occurring in their ecological space (Barni et al., 2020, Danioni et al., 2021), including perceiving life as meaningful, worth investing in and living in a productive manner. SOC consists of three main components: (1) Comprehensibility: the extent to which the individual perceives that events make logical sense and are ordered, coherent, and structured; (2) Manageability: the extent to which the individual has the feeling that all life events are somehow manageable and surmountable; (3) Meaningfulness: the extent to which the individual feels that life has meaning, and its challenges are worth the effort (Antonovsky, 1979).

SOC plays an important role within the family as a health-promoting factor. The family, indeed, is the primary context of socialization, in which children develop their representation of self, of others, and of the world on the basis of those held by their parents (Grusec \& Davidov, 2007). Several previous studies have shown that parents' SOC influences the quality of childrearing and child developmental outcomes (e.g., Arteche \& Murray, 2011, Belsky \& Pluess, 2012) and it is significantly associated with adolescents' psychological adjustment (e.g., Goldberg \& Wiseman, 2014, Olsson \& Hwang, 2002).

Especially during adolescence, the numerous physical and psychological changes experienced demand the establishment of new emotional and behavioral patterns and ways of conceptualizing these changes as manageable and meaningful tasks (Healy, 1989). Studies have confirmed the adaptive role of SOC, both on a familial and individual level (Antonovsky \& Sourani, 1988, Surtees et al., 2003). For example, Antonovsky \& Sourani (1988) found, in a sample of 60 families who faced a previous major stress or crisis, that families with higher scores in SOC also exhibited higher levels of adaptation. The data supported the hypothesis that families with higher SOC scores are more likely to adapt to situations, 
including restructuring the family pattern after a period of crisis, more quickly and efficiently than those with lower SOC scores. Individuals can draw upon the resource of family SOC in order to cope with various demands, especially when perceived as challenging and worthy of investment. According to the Antonovsky \& Sourani (1988), a strong SOC, particularly when held by parents (parental SOC), provides the perceptual, behavioral, and motivational bases for children's effective management of the demands posed by encountered stressors. For this reason, children of parents with high levels of SOC may benefit from parents being more adapted and satisfied with their family life and thus may also benefit from a higherquality parent-child relationship (Rosnati \& Barni, 2004). Parental SOC can be a model for children's development of coping strategies against stress and such coping strategies, in turn, may buffer the effects of violence victimization on shortand long-term emotional symptoms (Hemphill et al., 2014). Children whose parents hold a coherent sense of reality may therefore be - to a certain extent - protected against the negative effects of violence on their adjustment.

\section{The Current Study}

The literature on adolescent victimization has shown how violent experiences can be harmful for adolescents' adaptation (Buka et al., 2001, Ford et al., 2010, Turner et al., 2006), and particularly to their emotional functioning (e.g., Ghoul et al., 2013, Mrug \& Windle, 2010). We therefore expected adolescents' victimization to be positively associated with their internalizing problems. In addition, several studies on adolescent victimization have explored whether familial resources may buffer the negative outcomes of victimization (e.g., Hardaway et al., 2016, Zych et al., 2019). For example, parental support moderates the relation between victimization and depressive mood among adolescents (Claes et al., 2015). No studies to our knowledge have examined the role of parental SOC in this association. While family SOC has been associated with higher family adaptation (Antonovksy \& Sourani, 1988), it is also possible that fathers' and mothers' individual SOC play a specific part in this scenario, given that fathers and mothers are assumed to play different roles in children's socialization more generally (Cigoli \& Scabini, 2006). Some studies, for example, have indicated that fathers and mothers make unique contributions to children's socialization of coping strategies (e.g., Kliewer et al., 1996). While studies examining the relations of parental SOC with children's adjustment involved one parent at a time and mostly mothers (e.g., Al-Yagon, 2008, and, for one of the few studies on fathers' SOC, see Al-Yagon, 2011), to our knowledge no studies examined the specific contribution of both fathers' and mothers' SOC on adolescents' outcomes.
In light of this literature, in the present study we hypothesized that parental SOC would buffer the association of adolescents' victimization and internalizing problems. We expected that victimization would present weaker positive associations with adolescents' internalizing problems for those adolescents whose fathers and mothers reported higher levels of SOC.

\section{Method}

\section{Participants and Procedure}

We collected data for this study from March 2017 until May 2018 with the collaboration of three Italian high schools. Fathers, mothers, and adolescents each received questionnaire packets. We kept each questionnaire packet in a separate envelope to ensure anonymity. Adolescents completed the questionnaire at school, while their parents completed their questionnaires at home. Parents had the opportunity to phone researchers if they needed any help. All participants gave their informed consent in writing prior to inclusion in the study. Moreover, parents also signed an informed consent statement for their adolescent's participation.

We conducted the study in accordance with the Italian laws of privacy and informed consent (Law Decree DL-196/ 2003) and with the Italian Association of Psychology ethical guidelines. The study, which is a part of a larger project, was approved by the IRBs of all co-authors'institutions at the time of the study: Università Cattolica del Sacro Cuore (Milan, IT), Università LUMSA (Rome, IT), and Notre Dame University (Notre Dame, US) IRBs.

The sample included a total of 148 families with adolescents. Specifically, 128 fathers, 144 mothers, and 148 adolescents participated in the study. Adolescents $(87.7 \%$ girls) were between 15 and 19 years old $(M=17.3, \mathrm{SD}=0.76)$. The higher prevalence of girls than boys reflected the fact that we recruited most participants through two secondary schools that focused on humanities and social sciences, which had a higher prevalence of female students. Fathers were on average between 40 and 69 years old $(M=51.4, \mathrm{SD}=4.89)$ while mothers were between 37 and 60 years old $(M=48.92$, SD $=4.03)$. Parents were mostly married $(85.4 \%)$, separated/ divorced $(9 \%)$, single $(4.2 \%)$, or widowed $(1.4 \%)$. For those adults who reported to be married, the duration of the relationships reached an average of 21.16 years $(\mathrm{SD}=4.98)$.

\section{Measures}

\section{Violence victimization}

To measure adolescents' exposure to violence, adolescents replied to the question: "Below you will find a list of violent acts that people might suffer: Physical aggression, verbal 
aggression, sexual assault. Unfortunately, these episodes can happen, and it is difficult for those who experience violence to be able to protect themselves. Have you ever experienced personally one or more of these forms of violence?" (from $1=$ "No, never" to $3=$ "Yes, more than once").

\section{Peer victimization}

To measure adolescents' exposure to bullying and other forms of victimization among peers, adolescents replied to the question: "Sometimes people suffer because they are subject to bullying or are being treated badly by others. Below you will find a list of these experiences: Theft or damage of personal belongings, being picked on, being subjected to rumors or maladies. Have you ever experienced personally one or more of these forms of prevarication?" (from $1=$ "No, never" to $3=$ "Yes, more than once").

\section{Sense of coherence}

To measure fathers' and mothers' SOC, we used the Sense of Coherence Scale (Antonovsky, 1987; Italian validation by Barni \& Tagliabue, 2005). The scale consists of 13 items with a 7-step Likert-type response scale: the poles assume a different meaning depending on the items considered. For example, "When you do something that gives you a good feeling: (from $1=$ "It's certain that you will go on feeling good" to $7=$ "It's certain that something will happen to spoil the feeling"). Another example of an item is "Do you have a feeling that you are in an unfamiliar situation and don't know what to do? (from $1=$ "Very often" to $7=$ "Very seldom or never")". The scale comprises three different subscales: comprehensibility, manageability, and meaningfulness, all calculated by the sum score of the relative items. We computed a global index as the sum of the three subscale scores. Only the global index (separately calculated for the father and the mother) was used in the present study. We calculated the reliability of the scale through Cronbach's alpha, which was 0.80 (fathers) and 0.81 (mothers).

\section{Internalizing problems}

We assessed adolescents' internalizing problems in terms of negative emotional symptoms using the Strengths and Difficulties Questionnaire (SDQ) (Goodman, 1997; Italian validation by Tobia \& Marzocchi, 2018). The SDQ, which is a brief behavioral screening questionnaire for children and adolescents, was administered to parents (separately to the father and the mother). The subscale of emotional symptoms contains 5 items, on a 3-point Likert-type scale (from 1 $=$ "Not true" to $3=$ "Certainly true"), which refers to feelings of anxiety, depression, and anger. Item examples are:
"He/she has many fears and is easily scared" and "He/she is nervous in new situations, he/she easily loses confidence". The coefficient of reliability in terms of Cronbach's alpha was satisfactory ( $\alpha=0.64$ for fathers; $\alpha=0.67$ for mothers).

\section{Data Analysis}

We calculated descriptive statistics of the study variables and Pearson's product-moment correlation coefficients using SPSS version 23.0.

We used the path analysis (maximum likelihood estimation) to estimate the relations between adolescents' victimization (predictor variable), parents' SOC (moderator variables), and adolescents' internalizing problems as reported by parents (criteria variables). Two path analysis models were tested, the first with violence victimization and the second with peer victimization as predictors. To assess the moderation effect of parental SOC, we centered the predictors and moderators on their means before computing and entering their interaction terms into the models (Aiken \& West, 1991). In the analysis we controlled for adolescent's sex and age. Path coefficients and moderation effects were estimated using Amos version 23.0. We used chisquare $\left(\chi^{2}\right)$, Root Mean Square Error of Approximation (RMSEA), goodness of fit index (GFI), Tucker-Lewis index (TLI), and the nonnormed comparative fit indices (CFI) to assess the model fit. By convention, there is a good model fit if $\chi^{2}$ is not significant, RMSEA is less than or equal to 0.05 , and values for GFI, TLI, and CFI are greater than 0.90 (Bentler, 1990). Simple slope analysis was performed to probe any significant interaction effect.

\section{Results}

Means, standard deviations, and correlations among study variables are reported in Table 1. Thirty-seven percent of adolescents experienced one or more acts of violence (i.e., physical aggression, verbal aggression, or sexual assault). Percentages of adolescents exposed to peer victimization (i.e., theft or damage of personal belongings, being picked on, being subjected to rumors or maladies) was greater (74.4\%), showing that peer victimization experiences were quite common among adolescents involved in the study. A paired sample t-test indicated that adolescents experienced significantly more peer victimization than violence victimization, $t(147)=8.59, p=0.000$. However, the analysis showed a significant positive correlation between the two different types of victimization (violence vs. peer victimization) $(r=0.29, p=0.000)$.

Negative correlations were found between SOC, both paternal and maternal, and adolescents' internalizing problems as reported by fathers and mothers (from $r=-0.38, p=0.000$ 
Table 1 Means (M), standard deviations (SD), and correlations (Pearson's r) of parents' variables and adolescents' victimization
Fig. 1 Results of the path analysis with violence victimization as predictor. $* * * p<0.001, * * p<0.01$, $* p<0.05$. Unstandardized coefficients are presented. Int. problems Internalizing problems, Violence v. Violence victimization. Sex, age, and violence victimization were reported by adolescents

\begin{tabular}{|c|c|c|c|c|c|c|c|c|}
\hline & $M$ & SD & 1 & 2 & 3 & 4 & 5 & 6 \\
\hline 1. Adolescents' Violence Victimization & 1.58 & 0.81 & - & & & & & \\
\hline 2. Adolescents' Peer Victimization & 2.28 & 0.85 & $0.29 * *$ & - & & & & \\
\hline 3. Fathers' Sense of Coherence & 65.17 & 9.95 & 0.01 & -0.04 & - & & & \\
\hline 4. Mothers' Sense of Coherence & 62.24 & 11.02 & 0.07 & -0.05 & $0.19 *$ & - & & \\
\hline $\begin{array}{l}\text { 5. Fathers' Perception of Adolescents' } \\
\text { Internalizing Problems }\end{array}$ & 2.59 & 2.09 & 0.09 & 0.15 & $-0.31 * *$ & $-0.25 * *$ & - & \\
\hline $\begin{array}{l}\text { 6. Mothers' Perception of Adolescents' } \\
\text { Internalizing Problems }\end{array}$ & 2.97 & 1.58 & 0.03 & $0.19^{*}$ & $-0.26^{* *}$ & $-0.38 * *$ & $0.57 * *$ & - \\
\hline
\end{tabular}

$* * p<0.01, * p<0.05$. Victimization was reported by adolescents

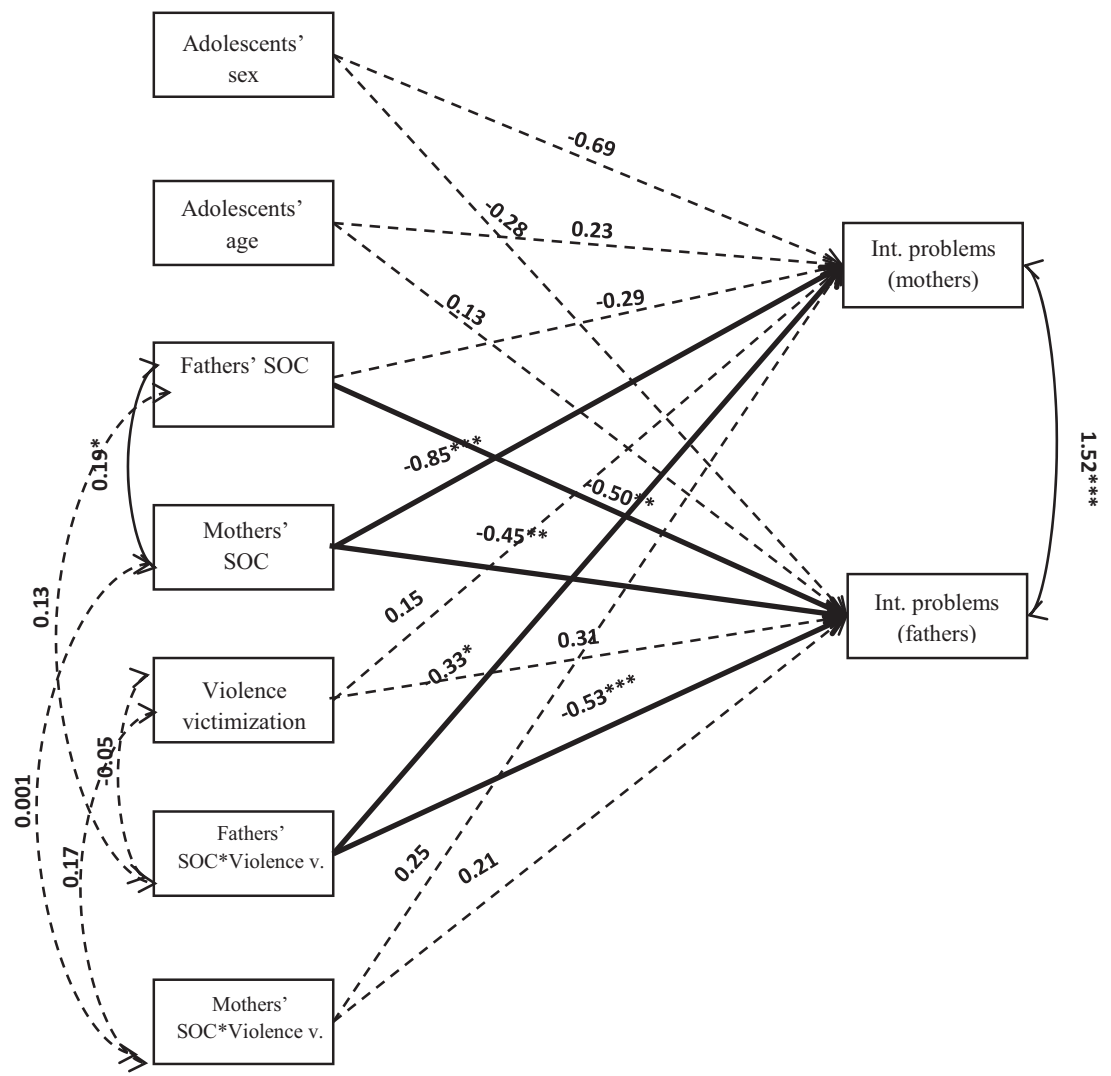

between mothers' SOC and mothers' perception of adolescents' internalizing problems to $r=-0.25, p=0.005$ between mothers' SOC and fathers' perception of adolescents' internalizing problems). Fathers' SOC was positively related to mothers' SOC ( $r=0.19, p=0.031)$ as well as fathers' perception of adolescents' internalizing problems was strongly and positively correlated to mothers' perceptions $(r=0.57$, $p=0.000)$.

\section{Violence victimization}

The results of the path analysis with violence victimization as predictor are presented in Fig. 1. This model had a good fit with a $\chi^{2}=17.49(\mathrm{df}=16, p=0.354)$, RMSEA $=0.029$, $\mathrm{GFI}=0.97, \mathrm{TLI}=0.96$, and $\mathrm{CFI}=0.98$. Mothers' SOC was directly and negatively related to both mothers' and fathers' perception of adolescents' internalizing problems: the more mothers were able to understand and integrate, to handle, and to make sense of experiences, the less mothers and fathers reported adolescents' problems. Fathers' SOC was directly and negatively associated with fathers' perception of adolescents' internalizing problems. Moreover, fathers' SOC - but not mothers' SOC - moderated the relations between adolescents' violence victimization and both parents' reporting of adolescents' internalizing problems.

Simple slope analysis indicated that when fathers had low levels of SOC (1 standard deviation below the mean), adolescents' violence experience was strongly, positively, and significantly associated with fathers' perception of 


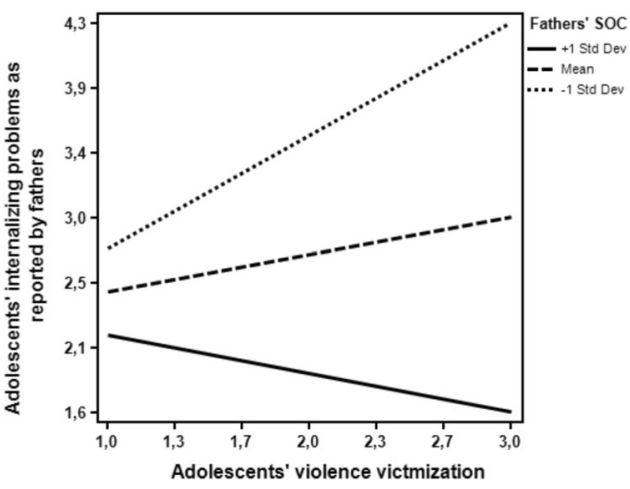

Fig. 2 Interaction effect between violence victimization and paternal sense of coherence on adolescents' internalizing problems (reported by fathers)

adolescents' internalizing problems (simple slope: 0.79, $p=0.008)$. On the contrary, for adolescents whose fathers had high levels of SOC (1 standard deviation above the mean) there was not any significant relation between adolescents' violence experiences and internalizing problems as reported by fathers (simple slope: $-0.27, p=0.355$; Fig. 2). Similarly, when fathers had low levels of SOC, adolescents' violence experience was stronger positively associated with mothers' perception of adolescents' internalizing problems (simple slope: $0.33, p=0.148$ ). On the contrary, for adolescents whose fathers had high levels of SOC the relation between adolescents' violence experiences and internalizing problems as reported by mothers was not significant at all (simple slope: $-0.16, p=0.614$; Fig. 3).

\section{Peer victimization}

The results of the path analysis with peer victimization as predictor are presented in Fig. 4. The model had a good fit with a $\chi^{2}=14.36(\mathrm{df}=16, p=0.572)$, RMSEA $=0.000$, $\mathrm{GFI}=0.97$, TLI $=1.04$, and $\mathrm{CFI}=1.00$. As already highlighted for the first model, mothers' SOC was directly and negatively related to both mothers' and fathers' perception of internalizing problems, while fathers' SOC was directly and negatively associated with fathers' reporting of internalizing problems, but not with mothers'. Fathers' SOC significantly moderated the relation between adolescents' peer victimization and fathers' perception of adolescents' internalizing problems.

Simple slope analysis indicated that when fathers had low levels of SOC (1 standard deviation below the mean), adolescents' peer victimization experience was strongly, positively, and significantly associated with fathers' perception of adolescents' internalizing problems (simple slope: $0.93, p=0.003)$. On the contrary, for adolescents whose fathers had high levels of SOC (1 standard deviation above the mean) there was not any significant relation

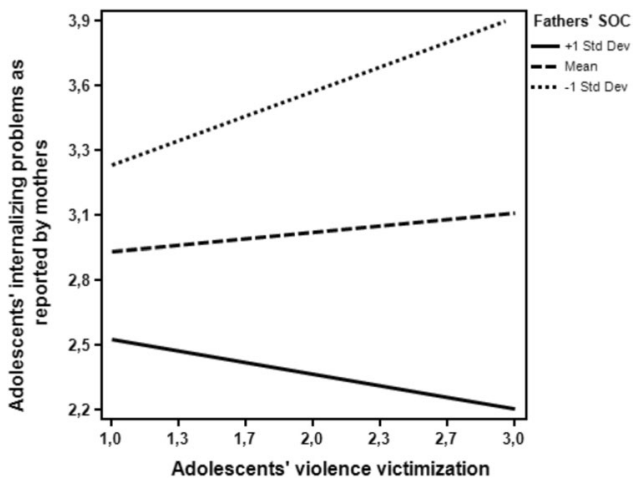

Fig. 3 Interaction effect between violence victimization and paternal sense of coherence on adolescents' internalizing problems (reported by mothers)

between adolescents' peer victimization experiences and internalizing problems as reported by fathers (simple slope: $-0.07, p=0.814$; Fig. 5).

\section{Discussion}

Research has generally reported that adolescents who are victims of violence and peer victimization are at a great risk of developing emotional and behavioral problems (e.g., Lätsch et al., 2017, Pham \& Adesman, 2015). The aim of this study was to examine the role of parents' SOC as protective factor in the relation between adolescents' victimization and their internalizing problems. We considered both severe violence experiences such as physical aggression, verbal aggression, sexual assault, and peer victimization experiences such as theft or damage of personal belongings, being picked on, being subjected to rumors or maladies.

Our study results suggest that the association between adolescents' victimization and internalizing problems (as reported by parents) differs across adolescents with varying levels of family protective factors. The most prominent result refers to the moderating role of fathers' SOC in this association. Adolescents' victimization (both forms) was indeed positively associated with internalizing problems only when fathers had low levels of SOC. On the contrary, when fathers had a strong feeling of confidence that life events are predictable and that there is a high probability that things will work out as well as it can reasonably be expected (i.e., high SOC), adolescents' victimization was not significantly related to internalizing problems. Interestingly, in the case of violence victimization, fathers' SOC tended to act as a buffer in reducing the impact of adolescents' victimization on both fathers' and mothers' perceptions of adolescents' internalizing problems. Thus, father's SOC may be especially important as family resource when 
Fig. 4 Results of the path analysis with peer victimization as predictor. $* * * p<0.001$, $* * p<0.01, * p<0.05$.

Unstandardized coefficients are presented. Int. problems Internalizing problems, Peer v. Peer victimization. Sex, age, and peer victimization were reported by adolescents

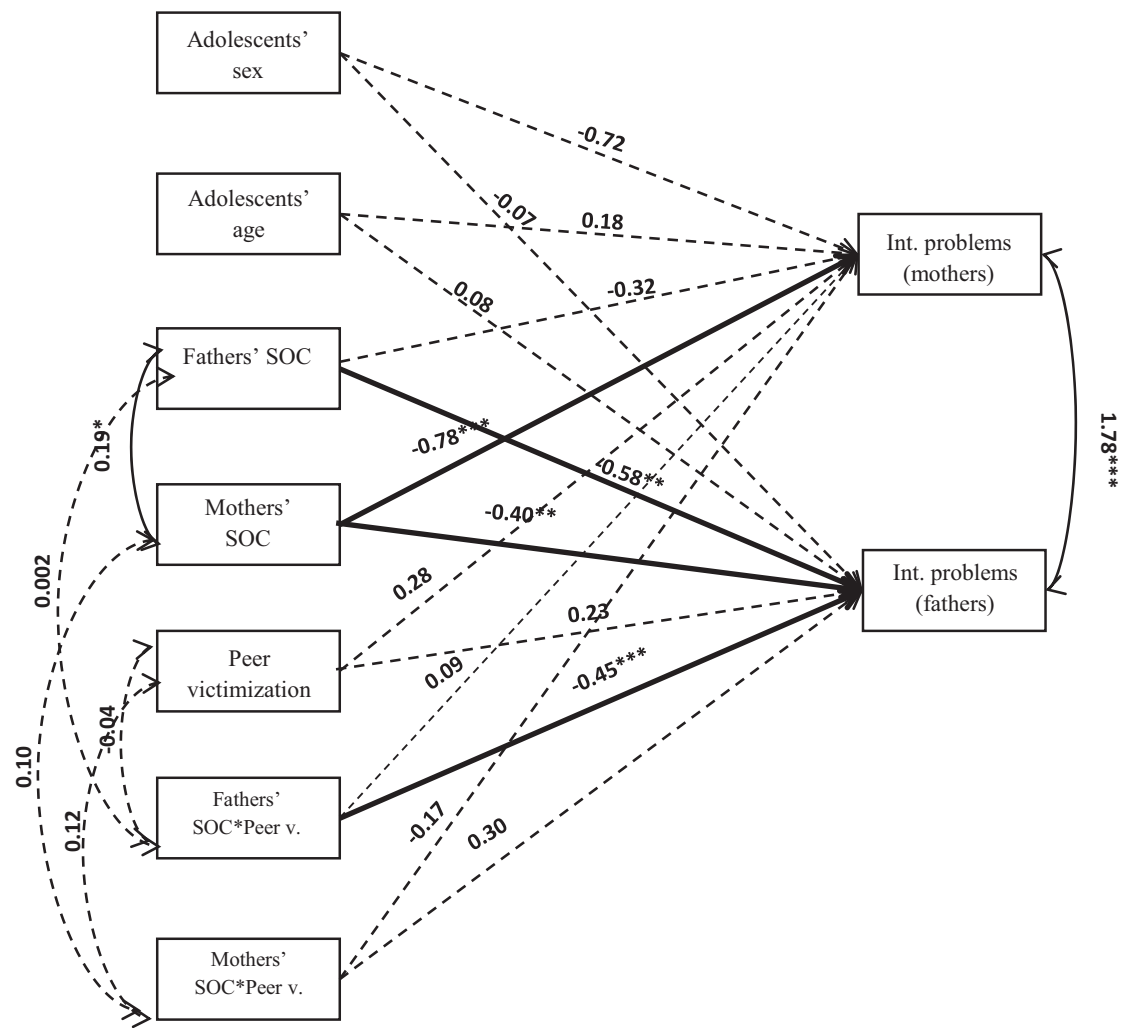

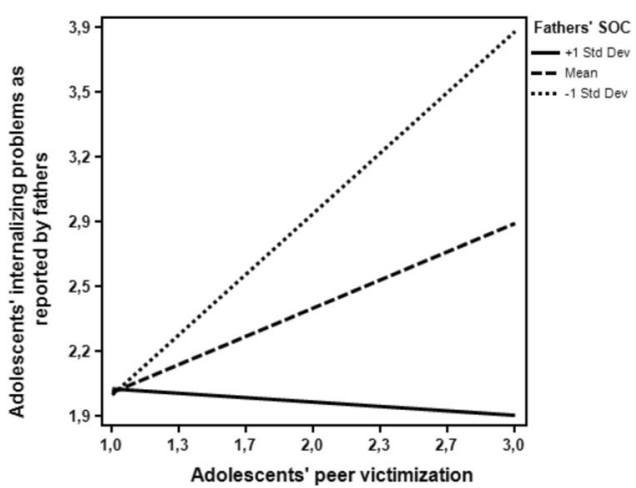

Fig. 5 Interaction effect between peer victimization and paternal sense of coherence on adolescents' internalizing problems (reported by fathers)

the adolescent is exposed to violence. This result is in line with the normative and protective role of the father figure within the family, in which he plays the role of mediator with the social and external world (Scabini \& Cigoli, 2000). Previous research focused on chronical stressful situations (e.g., child disabilities; O'Halloran et al., 2103) also suggested the positive role of paternal manifestations of optimism, confidence in one's resources, and hope. The way the father perceives the social reality is therefore important for the adolescent, especially when this reality becomes stressful and the adolescent is exposed to violence and/or peer victimization experiences. In these cases, the father's ability to comprehend, manage, and give meaning to the world and its events especially benefits the adolescent's adaptation. High-SOC fathers could help adolescents to impose structure on the stressful situation and to search for resources that could help them overcome the stressors.

Another line of interpretation of the especially salient role of fathers in this study could refer to the characteristics of the selected sample: most of adolescent participants, in fact, were girls. Togari et al. (2011) argued that, in its transmission, maternal SOC was directly related to their son's SOC, whereas only an indirect relationship through the adolescent's participation in decision-making at home was found between mother's and daughter's SOC. Parental SOC may therefore be more strongly transmitted between different-sex parent-adolescent dyads than same-sex parentadolescent dyads. As such, parental SOC transmission may be especially salient from mother to son and from father to daughter. This may help to explain the study findings, whereby in our prevalently female sample fathers' SOC played a protective role for adolescents while mothers' SOC did not. This argument deserves further empirical research to learn more about the direction of intergenerational transmission and the links between parents' and children's sex.

Maternal SOC did not moderate the association between victimization and adolescents' internalizing problems. However, it was directly and negatively related to both parents' perception of adolescents' internalizing problems 
as well as fathers' SOC was negatively related to their own perception of adolescents' internalizing problems. Antonovsky and Sourani (1988) argued that a strong familial SOC, especially the one shared in the interparental relationship, provides perceptive, behavioral, and motivational bases for effective management of the demands deriving from parenting duties. The ability to respond more consistently to these demands improves not only parents' stress resistance, but also the general well-being of the entire family. Research involving 128 Chinese childbearing couples supported this idea: Couples with a greater sense of coherence were better able to withstand stress. Moreover, SOC plays a pivotal role in promoting family functioning and reducing depressive symptoms during the transition to parenthood (Ngai \& Ngu, 2011). SOC develops in the individual at a very early age, with the purpose of giving stability and making external and internal reality more predictable (or as predictable as possible), following the parental response to the child's actions.

\section{Limitations}

The present findings need to be interpreted considering the study limitations. First, the sample was composed mostly of middle-class families with female adolescents, and so the findings need to be replicated with a more diverse sample in order to generalize the results to a wider population. Second, adolescents' violence and peer victimizations were based only on single items. This is a major limitation of our study, given that single items cannot tap the different nuances of the victimization, providing more vague indicators of it as compared to multi-item scales. Moreover, single-item measures do not allow examination of psychometric properties in terms of reliability. Future research should examine the current associations by using multi-item victimization measures. In addition to the drawbacks of a single-item measure, moreover, we measured adolescents' internalizing problems through parents' perceptions only. Common method variance could partially explain the link between parent-reported SOC and parent-reported adolescents' internalizing problems. Confidence in our results, however, derives from the use of adolescent-reported victimization as well as from the fact that common method variance should have worked for both parents. The interaction between mothers' SOC and victimization, indeed, did not predict adolescents' internalizing problems, even when mothers reported it. It would nonetheless be useful, in future studies, to confirm our findings with childrenreported measures of internalizing symptoms as well, since literature has shown that parents' and children's reports of adjustment and mental health may differ and complement each other in the assessment of children's wellbeing (Becker et al., 2004). Third, self-report questionnaires can be subject to the social desirability and retrospective bias of the reporter. Finally, the correlational nature of the present study makes it impossible to underline causal relationships.

\section{Strengths and implications for intervention}

The current study, however, presents a major strength in that it considered both victimization and resources together, including resilience factors of both fathers and mothers. The role of parental SOC in protecting victimized adolescents has not been previously tested empirically, particularly considering both fathers and mothers. Moreover, findings from this study have implications for the interventions focused on the family and on the adolescent. Family context can play a key role in creating consistency and a safe environment that enhances SOC. A special aim for interventions could be to strengthen parents' SOC so they can provide their adolescents with a coping resource for when adolescents face stressful events. If the present results in the future are supported in more sex-balanced samples, interventions could also make parents aware of the important role of fathers, and particularly of the representation of the social reality they convey to adolescents in stressful circumstances. As described by Mayer and Boness (2012), individual SOC can be improved through health promotion practices including goal setting, problem solving, active coping, healthy communication, managing health, advocacy, and maintenance. Several salutogenic training programs, referring especially to educational and rehabilitation contexts, have been published (e.g., HEDE, Franke and Witte (2009); VINN, Højdahl et al., 2013). Moreover, various empirical studies showed that mindfulness-based stress reduction programs (e.g., Weissbecker et al., 2002) and psycho-therapeutic interventions (psychodynamic therapies, Sack et al., 1997; or behavioral therapies, Wiesmann et al., 2006) can enhance individual SOC. Interestingly, according to Krause and Lorenz (2009), not only professionals, but also people in daily interactions (such as parents) can give a relevant contribution to support adolescents' SOC by acknowledging, comprehending, accepting, and supporting the adolescent in daily life. As for professional interventions specifically focused on adolescents, they can increase adolescents' awareness of their familial and parental resources as well as to promote adolescents' own SOC, especially when adolescents experience low levels of SOC at home. In addition, interventions can also raise awareness of the high proportion of adolescents exposed to victimization such as violence and peer victimization, which may lead to adolescents being more open about such delicate themes and subjects. Such a knowledge could empower adolescents to better use their resources and improve their functioning at different ecological levels. 


\section{Data Availability}

The raw data supporting the conclusions of this article will be made available upon request to the first author, without undue reservation.

Author Contributions S.D., A.F., and R.I. collected the data. S.D. conducted the data analysis. All authors contributed to the writing of the article and approved the submitted version.

\section{Compliance with Ethical Standards}

Conflict of Interest The authors declare no competing interests.

Ethical Approval This research was approved by the IRBs of all coauthors' institutions at the time of the study: Università Cattolica del Sacro Cuore (Milano, IT), Università LUMSA (Roma, IT), and Notre Dame University (Notre Dame, US) IRBs.

Informed Consent All participants provided written informed consent.

Publisher's note Springer Nature remains neutral with regard to jurisdictional claims in published maps and institutional affiliations.

Open Access This article is licensed under a Creative Commons Attribution 4.0 International License, which permits use, sharing, adaptation, distribution and reproduction in any medium or format, as long as you give appropriate credit to the original author(s) and the source, provide a link to the Creative Commons license, and indicate if changes were made. The images or other third party material in this article are included in the article's Creative Commons license, unless indicated otherwise in a credit line to the material. If material is not included in the article's Creative Commons license and your intended use is not permitted by statutory regulation or exceeds the permitted use, you will need to obtain permission directly from the copyright holder. To view a copy of this license, visit http://creativecommons. org/licenses/by/4.0/.

\section{References}

Aiken, L. S., \& West, S. G. (1991). Multiple regression: Testing and interpreting interactions. Sage.

Al-Yagon, M. (2008). Maternal personal resources and children's socioemotional and behavioral adjustment. Child Psychiatry and Human Development, 39(3), 283-298. https://doi.org/10.1007/ s10578-007-0088-z.

Al-Yagon, M. (2011). Fathers' emotional resources and children's socioemotional and behavioral adjustment among children with learning disabilities. Journal of Child and Family Studies, 20(5), 569-584. https://doi.org/10.1007/s10826-010-9429-9.

Antonovsky, A. (1979). Health, stress, and coping. Jossey-Bass.

Antonovsky, A. (1987). Unraveling the mystery of health. JosseyBass.

Antonovsky, A. (1996). The salutogenic model as a theory to guide health promotion. Health Promotion International, 11(1), 11-18. https://doi.org/10.1093/heapro/11.1.11.

Antonovsky, A., \& Sourani, T. (1988). Family sense of coherence and family adaptation. Journal of Marriage and the Family, 50(1), 79-92. https://doi.org/10.2307/352429.

Arteche, A., \& Murray, L. (2011). Maternal affective disorder and children's representation of their families. Journal of Child and
Family Studies, 20(6), 822-832. https://doi.org/10.1007/s10826011-9450-7.

Barni, D., Danioni, F., Canzi, E., Ferrari, L., Ranieri, S., Lanz, M., Iafrate, R., Regalia, C., \& Rosnati, R. (2020). Facing the COVID19 pandemic: The role of sense of coherence. Frontiers in Psychology, 11, 578440. https://doi.org/10.3389/fpsyg.2020.578440.

Barni, D., \& Tagliabue, S. (2005). Sense of coherence Scale di Antonovsky: Un contributo alla validazione italiana [Antonovsky's Sense of Coherence Scale: A contribution to the Italian validation]. T.P.M. Testing, Psychometrics, Methodology in Applied Psychology, 3, 151-166.

Becker, A., Hagenberg, N., Roessner, V., Woerner, W., \& Rothenberger, A. (2004). Evaluation of the self-reported SDQ in a clinical setting: Do self-reports tell us more than ratings by adult informants? European Child \& Adolescent Psychiatry, 13(2), ii17-ii24. https://doi.org/10.1007/s00787-004-2004-4.

Belsky, J., \& Pluess, M. (2012). Differential susceptibility to long-term effects of quality of childcare on externalizing behavior in adolescence? International Journal of Behavioral Development, 36 (1), 2-10. https://doi.org/10.1177/0165025411406855.

Bentler, P. M. (1990). Comparative fit indexes in structural models. Psychological Bulletin, 107(2), 238-246. https://doi.org/10.1037/ 0033-2909.107.2.238.

Buka, S. L., Stichick, T. L., Birdthistle, I., \& Earls, F. J. (2001). Youth exposure to violence: Prevalence, risks, and consequences. American Journal of Orthopsychiatry, 71(3), 298-310. https:// doi.org/10.1037/0002-9432.71.3.298.

Cigoli, V., \& Scabini, E. (2006). Family Identity: Ties, symbols, and transitions. Lawrence Erlbaum Associates.

Claes, L., Luyckx, K., Baetens, I., Van de Ven, M., \& Witteman, C. (2015). Bullying and victimization, depressive mood, and nonsuicidal self-injury in adolescents: The moderating role of parental support. Journal of Child and Family Studies, 24(11), 3363-3371. https://doi.org/10.1007/s10826-015-0138-2.

Danioni, F., Sorgente, A., Barni, D., Canzi, E., Ferrari, L., Ranieri, S., Iafrate, R., Regalia, C., Rosnati, R., \& Lanz, M. (2021). Sense of coherence and COVID-19: A longitudinal study. Journal of Psychology: Interdisciplinary and Applied, 155(7), 657-677. https://doi.org/10.1080/00223980.2021.1952151.

de Silva, A. D., Mengyu, M. G., Barni, D., Donato, S., Miller-Graff, L. E., \& Cummings, E. M. (2020). Interparental conflict on Italian adolescent adjustment: The role of insecurity within the family. Journal of Family Issues, 42(3), 671-692. https://doi.org/10. 1177/0192513X20927749.

Ehrensaft, M. K., Cohen, P., Brown, J., Smailes, E., Chen, H., \& Johnson, J. G. (2003). Intergenerational transmission of partner violence: A 20-year prospective study. Journal of Consulting and Clinical Psychology, 71(4), 741-753. https://doi.org/10.1037/ 0022-006X.71.4.741.

Elkind, D. (1967). Egocentrism in adolescence. Child Development, 38(4), 1025-1034. https://doi.org/10.2307/1127100.

Erikson, E. (1968). Identity: Youth and crisis. W.W. Norton \& Company.

Evans, S. E., Davies, C., \& DiLillo, D. (2008). Exposure to domestic violence: A meta-analysis of child and adolescent outcomes. Aggression and Violent Behavior, 13(2), 131-140. https://doi. org/10.1016/j.avb.2008.02.005.

Flannery, D., Wester, K., \& Singer, M. (2004). Impact of violence exposure at school on child mental health and violent behavior. Journal of Community Psychology, 32(5), 559-574. https://doi. org/10.1002/jcop.20019.

Ford, J. D., Elhai, J. D., Connor, D. F., \& Frueh, B. C. (2010). Polyvictimization and risk of posttraumatic, depressive, and substance use disorders and involvement in delinquency in a national sample of adolescents. Journal of Adolescent Health, 46(6), 545-552. https://doi.org/10.1016/j.jadohealth.2009.11.212. 
Fowler, P. J., Tompsett, C. J., Braciszewski, J. M., Jacques-Tiura, A. J., \& Baltes, B. B. (2009). Community violence: A meta-analysis on the effect of exposure and mental health outcomes of children and adolescents. Development \& Psychopathology, 21(1), 227-259. https://doi.org/10.1017/S0954579409000145.

Franke, A., \& Witte, M. (2009). Das HEDE-Training ${ }^{\circledR}$. Manual zur Gesundheitsförderung auf Basis der Salutogenese [The HEDETraining ${ }^{\circledR}$. Manual for health promotion based on salutogenesis]. Huber

Ghoul, A., Niwa, E. Y., \& Boxer, P. (2013). The role of contingent self-worth in the relation between victimization and internalizing problems in adolescents. Journal of Adolescence, 36(3), 457-464. https://doi.org/10.1016/j.adolescence.2013.01.007.

Goldberg, A., \& Wiseman, H. (2014). Parents' sense of coherence and the adolescent's health and emotional and behavioral adjustment: The case of adolescents with diabetes. Journal of Pediatric Nursering, 29(5), 15-21. https://doi.org/10.1016/j.pedn.2014.01. 004.

Goodman, R. (1997). The strengths and difficulties questionnaire: A research note. Journal of Child Psychology and Psychiatry, 38(5), 581-586. https://doi.org/10.1111/j.1469-7610.1997.tb01545.x.

Gorman-Smith, D., \& Tolan, P. (1998). The role of exposure to community violence and developmental problems among innercity youth. Development and Psychopathology, 10(1), 101-116. https://doi.org/10.1017/S0954579498001539.

Graham, S., \& Juvonen, J. (1998). Self-blame and peer victimization in middle school: An attributional analysis. Developmental Psychology, 34(3), 587-599. https://doi.org/10.1037/0012-1649.34. 3.587 .

Grusec, J. E., \& Davidov, M. (2007). Socialization in the family: The roles of parents. In: J. E. Grusec \& P. D. Hastings (Eds.), Handbook of socialization: Theory and research (pp. 284-308). Guilford Press.

Hamby, S., Taylor, E., Jones, L., Mitchell, K. J., Turner, H. A., \& Newlin, C. (2018). From poly-victimization to poly-strengths: Understanding the web of violence can transform research on youth violence and illuminate the path to prevention and resilience. Journal of Interpersonal Violence, 33(5), 719-739. https:// doi.org/10.1177/0886260517744847.

Hardaway, C. R., Sterrett-Hong, E., Larkby, C. A., \& Cornelius, M. D. (2016). Family resources as protective factors for low-income youth exposed to community violence. Journal of Youth and Adolescence, 45(7), 1309-1322. https://doi.org/10.1007/s10964015-0410-1.

Healy, J. M. (1989). Emotional adaptation to life transitions: Early impact on integrative cognitive processes. In: D. M. Buss \& N. Cantor (Eds.), Personality psychology (pp. 115-127). Springer.

Hemphill, S. A., Tollit, M., \& Herrenkohl, T. I. (2014). Protective factors against the impact of school bullying perpetration and victimization on young adult externalizing and internalizing problems. Journal of School Violence, 13(1), 125-145. https:// doi.org/10.1080/15388220.2013.844072.

Hillis, S., Mercy, J., Amobi, A., \& Kress, H. (2016). Global prevalence of past-year violence against children: A systematic review and minimum estimates. Pediatrics, 137(3), e20154079 https://doi.org/10.1542/peds.2015-4079.

Højdahl, T., Magnus, J. H., Hagen, R., \& Langeland, E. (2013). "A bridge to change": Experiences of participation in "VINN"- a motivational program for convicted women. A qualitative study. EuroVista, 2(3), 177-190.

Janosz, M., Archambault, I., Pagani, L. S., Pascal, S., Morin, A. J. S., \& Bowen, F. (2008). Are there detrimental effects of witnessing school violence in early adolescence? Journal of Adolescent Health, 43(6), 600-608. https://doi.org/10.1016/j.jadohealth. 2008.04.011.
Källström, ̊̊., Hellfeldt, K., Howell, K. H., Miller-Graff, L. E., \& Graham-Bermann, S. A. (2020). Young adults victimized as children or adolescents: Relationships between perpetrator patterns, poly-victimization, and mental health problems. Journal of Interpersonal Violence, 35(11-12), 2335-2357. https://doi.org/ $10.1177 / 0886260517701452$.

Kliewer, W., Fearnow, M. D., \& Miller, P. A. (1996). Coping socialization in middle childhood: Tests of maternal and paternal influences. Child Development, 67(5), 2339-2357. https://doi. org/10.2307/1131627.

Krause, C., \& Lorenz, R. F. (2009). Was Kindern Halt gibt. Salutogenese in der Erziehung [What supports children. Salutogenesis in education]. V\&R.

Lätsch, D. C., Nett, J. C., \& Hümbelin, O. (2017). Poly-victimization and its relationship with emotional and social adjustment in adolescence: Evidence from a national survey in Switzerland. Psychology of Violence, 7(1), 1-11. https://doi.org/10.1037/a 0039993.

Mayer, C.-H., \& Boness, C. (2012). Interventions to promoting sense of coherence and transcultural competences in educational contexts. International Review of Psychiatry, 23(6), 516-524. https:// doi.org/10.3109/09540261.2011.637906.

Masten, A. S. (2015). Ordinary magic: Resilience in development. Guilford Publications.

Mrug, S., \& Windle, M. (2010). Prospective effects of violence exposure across multiple contexts on early adolescents' internalizing and externalizing problems. Journal of Child Psychology and Psychiatry, 51(8), 953-961. https://doi.org/10.1111/j.14697610.2010.02222.x.

National Academies of Sciences, Engineering, and Medicine (2016). Preventing bullying through science, policy, and practice. The National Academies Press. https://doi.org/10.17226/23482.

Ngai, F., \& Ngu, S. (2011). Translation and validation of a Chinese version of the family sense of coherence scale in Chinese childbearing families. Nursing Research, 60(5), 295-301. https://doi. org/10.4236/ojn.2016.612102.

O'Halloran, M., Sweeney, J., \& Doody, O. (2103). Exploring fathers' perceptions of parenting a child with Asperger syndrome. Journal of Intellectual Disabilities, 17(3), 198-213. https://doi.org/10. 1177/1744629513494928.

Olsson, M. B., \& Hwang, C. P. (2002). Sense of coherence in parents of children with different developmental disabilities. Journal of Intellectual Disability Research, 46(7), 548-559. https://doi.org/ 10.1046/j.1365-2788.2002.00414.x.

Patel, M. M., Liddell, J. L., \& Ferreira, R. J. (2018). An evaluation of the positive action program for youth violence prevention: From schools to summer camps. Child and Adolescent Social Work Journal, 35(5), 519-530. https://doi.org/10.1007/s10560-0180536-6.

Pham, T., \& Adesman, A. (2015). Teen victimization: Prevalence and consequences of traditional and cyberbullying. Current Opinion in Pediatrics, 27(6), 748-756. https://doi.org/10.1097/MOP. 0000000000000290.

Rigby, K. (2003). Consequences of bullying in school. The Canadian Journal of Psychiatry, 48(9), 583-590. https://doi.org/10.1177/ 070674370304800904.

Rosnati, R. \& Barni, D. (2004). Relazioni familiari e percezione del mondo sociale in coppie con figli in età scolare e adolescenziale [Family relations and perception of the social world in couples with school-aged and adolescent children]. Terapia Familiare [Family Therapy], 75, 65-84.

Sack, M., Künsebeck, H. W., \& Lamprecht, F. (1997). Kohärenzgefühl und psychosomatischer Behandlungserfolg. Eine empirische Untersuchung zur Salutogenese [Sense of coherence and psycho-somatical treatment success. An empirical research of 
salutogenesis]. Psychotherapie, Psychosomatik, Medizinische Psychologie, 47, 149-155.

Scabini, E., \& Cigoli, V. (2000). Il Famigliare. Legami, simboli e transizioni [The family. Bonds, symbols, and transitions]. Raffaello Cortina Editore.

Surtees, P., Wainwright, N., Luben, R., Khaw, K. T., \& Day, N. (2003). Sense of coherence and mortality in men and women in the EPIC-Norfolk United Kingdom prospective cohort study. American Journal of Epidemiology, 158(12), 1202-1209. https:// doi.org/10.1093/aje/kwg272.

Tobia, V., \& Marzocchi, G. M. (2018). The strengths and difficulties questionnaire-parents for Italian school-aged children: Psychometric properties and norms. Child Psychiatry and Human Development, 49(1), 1-8. https://doi.org/10.1007/s10578-0170723-2.

Togari, T., Sato, M., Otemori, R., Yonekura, Y., Yokoyama, Y., Kimura, M., \& Yamazaki, Y. (2011). Sense of coherence in mothers and children, family relationships and participation in decision-making at home: An analysis based on Japanese parent-child pair data. Health Promotion International, 27(2), 148-156. https://doi.org/10.1093/heapro/daq081.

Turner, H. A., Finkelhor, D., \& Ormrod, R. (2006). The effect of lifetime victimization on the mental health of children and adolescents. Social Science \& Medicine, 62(1), 13-27. https://doi. org/10.1016/j.socscimed.2005.05.030.

Ungar, M. (Ed.) (2011). The social ecology of resilience: A handbook of theory and practice. Springer Science \& Business Media.

Wiesmann, U., Rölker, S., Ilg, H., Hirtz, P., \& Hannich, H. J. (2006). Zur Stabilität und Modifizierbarkeit des Köhärenzgefühls aktiver älterer Menschen [Stabilising and modifying the sense of coherence of active elderly human beings]. Zeitschrift für Gerontopsychologie und Psychiatrie, 39(2), 90-99. https://doi.org/ 10.1007/s00391-006-0322-5.

Weissbecker, J., Salmon, P., Studts, J. L., Floyd, A. R., Dedert, E. R., \& Sephton, S. E. (2002). Mindfulness - based stress reduction and sense of coherence among women with Fibromyalgia. Journal of Clinical Psychology in Medical Settings, 9(4), 297-307. https://doi.org/10.1023/A:1020786917988.

Wolfe, D. A., Crooks, C. V., Lee, V., McIntyre-Smith, A., \& Jaffe, P. G. (2003). The effects of children's exposure to domestic violence: A meta-analysis and critique. Clinical Child and Family Psychology Review, 6, 171-187. https://doi.org/10.1023/A:1024910416164.

Zych, I., Farrington, D. P., \& Ttofi, M. M. (2019). Protective factors against bullying and cyberbullying: A systematic review of metaanalyses. Aggression and Violent Behavior, 45, 4-19. https://doi. org/10.1016/j.avb.2018.06.008. 